\title{
Flexural Resistance Factors for Structural Ultra Lightweight Engineered Cementitious Composite Slabs
}

\author{
Bashar Behnam, Mohammed Al-Iessa* \\ Department of Civil Engineering, Philadelphia University, Amman, 19392, Amman, Jordan
}

Received February 11, 2021; Revised March 30, 2021; Accepted April 22, 2021

\section{Cite This Paper in the following Citation Styles}

(a): [1] Bashar Behnam, Mohammed Al-Iessa, "Flexural Resistance Factors for Structural Ultra Lightweight Engineered Cementitious Composite Slabs," Civil Engineering and Architecture, Vol. 9, No. 3, pp. 807-819, 2021. DOI: 10.13189/cea.2021.090322.

(b): Bashar Behnam, Mohammed Al-Iessa (2021). Flexural Resistance Factors for Structural Ultra Lightweight Engineered Cementitious Composite Slabs. Civil Engineering and Architecture, 9(3), 807-819. DOI: 10.13189/cea.2021.090322.

Copyright $\odot 2021$ by authors, all rights reserved. Authors agree that this article remains permanently open access under the terms of the Creative Commons Attribution License 4.0 International License

\begin{abstract}
Many problems associated with the use of normal weight concrete have been solved with the development of structural ultra-lightweight engineered cementitious composite (SULWECC) that has the capability to exhibit strain-hardening behavior prior to failure. However, the feasibility and standards that address the design of such engineered cementitious composites (ECC) in flexural slab systems are not available. In this study, reliability analysis and calibration process are carried out on three different SULWECC slab systems with the intention of estimating the potential flexural resistance factors. Although the high volume of randomly dispersed synthetic short fiber is considered the main reinforcement, SULWECC slab systems internally reinforced with carbon FRP mesh are also considered. The reinforcement ratio is selected so that the section is under-reinforced. Relevant load and resistance random variables are used, and appropriate statistical parameters are selected. The target reliability indices are chosen to be consistent with those used to develop current design code specifications. The nominal moment capacity is calculated based on a new model that consists of: elastic linear stress distribution in the compression zone and elastic-perfectly-plastic uniform stress distribution in the tension zone. The determined flexural resistance factors ranged from 0.59 to 0.69 , although higher values are justifiable in special circumstances. The average slab thickness needed to satisfy the strength requirements ranged from $1 / 37$ to $1 / 22$ times the slab length. Flexural toughness to measure ductility is evaluated using load-deflection curves of
\end{abstract}

experimentally tested SULWECC specimens.

Keywords Structural Ultra Lightweight, ECC, Carbon FRP, Mesh, Slab, Reliability, Toughness, Monte-Carlo

\section{Introduction}

Under certain circumstances and specific conditions, concrete members reinforced with steel bars are associated with significant corrosion maintenance costs. When steel bars corrode, a noticeable reduction in tensile strength as well as deterioration in the bond between concrete and reinforcing steel bars occurs. The result will be a section of reduced capacity. In addition, the products of steel corrosion (rust) can enlarge considerably, resulting in volume expansion of reinforcing steel bars. As the steel bars expand, the surrounding concrete is damaged and cracks are developed, causing a loss of bond strength between the concrete and steel, eventually leading to large pieces of concrete to break off [1]. As a consequence, replacement or strengthening becomes an unavoidable requirement. In order to overcome the corrosion problem, a number of practices have been implemented, including the addition of corrosion-preventing admixture, the increase of clear cover of concrete, or the use of treated steel, such as galvanized or epoxy-coated steel reinforcing bars. An alternative approach, which has gained some recognition in 
the last four decades around the world, is the use of fiber reinforced polymer (FRP) bars. Many of the disadvantages associated with use of FRP reinforcing bars have been overcome with the selection of proper materials and the use of new concepts in manufacturing processes [2,3]. Despite the availability of design codes and materials, the growth in the use of FRP bars, as a replacement to conventional steel, is remarkably slow. Factors that impede the use FRP bars are: absence of ductility, low modulus of elasticity, poor bond with concrete matrix, inadequate resistance to deterioration in alkaline environments, and lack of necessary knowledge among structural designers.

Engineered cementitious composite (ECC) is a high-performance fiber-reinforced cementitious composite that does not contain coarse aggregate and provides high ductility and high resistance to crack propagation. The design of such composite is controlled by micromechanics models that relate the composite mechanical behavior to the properties of individual components [4]. ECC utilizes the potential of synthetic short fibers to improve the properties of cementitious composite by increasing the ultimate tensile and compressive strain capacities. The use of structural ultra-lightweight ECC (SULWECC) in civil engineering applications is associated with many advantages, such as reduction in the total weight of the structure, reduction in the amount of reinforcement, decrease in the size of the structural elements, and the potential of reducing the damage to the structure caused by the dynamic forces, since dynamic forces and mass of structures are proportional [5]. All these factors combined will result in cost saving opportunities. Ultra-lightweight ECC (ULWECC) has a very low thermal conductivity (less than $0.17 \mathrm{~W} /(\mathrm{m} \cdot \mathrm{K})$ ) which makes it an excellent thermal insulation material $[6,7]$.

Structural lightweight aggregate concrete is concrete that has a minimum 28-day compressive strength of 17 $\mathrm{MPa}$, and a density between 1120 and $1920 \mathrm{~kg} / \mathrm{m}^{3}$ [8]. Although there is not a specific definition for ULWECC with structural properties, this study refers to it as cementitious composite that has a compressive strength greater than or equal to $17 \mathrm{MPa}$ and a density less than $1120 \mathrm{~kg} / \mathrm{m}^{3}$.

Deterministic analysis methods fail to determine the absolute safety for the design service life of structural members due to the inherited uncertainties associated with load effects, resistance capacity, and method of analysis. In contrast, reliability-based design of structures can successfully measure the uncertainties that are implicitly incorporated into the analysis and design of any structural member, to ensure the structural component will serve the function for which it is intended to. To the authors' knowledge, until now no reliability analysis and calibration process have been conducted to evaluate the flexural resistance factor of SULWECC slab systems internally reinforced with FRP materials, and only a small number of studies have addressed FRP reinforced ECC including [9] and [10]. However, flexural resistance factors were evaluated for different grade concrete members reinforced with FRP bars [11-13].

\section{Study Significance and Objectives}

A research program was developed to determine the flexural resistance factors for corrosion-free, SULWECC slab systems that have the ability to exhibit noticeable strain-hardening behavior prior to failure and maintain very low self-weight to meet the ACI-440.1R [14] and ACI-318 [15] flexural strength requirements and safety levels. SULWECC is expected to be an alternative design option when ductile ultra-lightweight structural material is needed. The findings of this study can be utilized to estimate what design benefit might be obtained, in terms of flexural resistance factor, by using SULWECC slabs over normal weight concrete (NWC) slabs reinforced with steel or FRP bars. This research aims to contribute to the increase of knowledge to this area.

\section{Research Methodology}

Three different SULWECC slab systems are proposed with the intention of evaluating the flexural resistance factors $(\phi)$ using reliability analysis and calibration process. Both cast-in-place and precast SULWECC slab systems are investigated. Although the high volume of randomly dispersed synthetic short fiber is considered the main reinforcement (usually $2 \%$ volume fraction), slab systems internally reinforced with carbon FRP (CFRP) mesh are also considered. The reinforcement ratio $\left(\rho_{f}\right)$ of the CFRP is selected so that the section is under-reinforced. The reinforcement ratio can be calculated using $\rho_{f}=A_{f} / b d$, where $A_{f}$ is the area of reinforcement, $b$ is the slab width and $d$ is the reinforcement effective depth. The environmental factor $\left(C_{E}\right)$ to account for material degradation of CFRP mesh was taken 1.0. Rectangular, simple span slabs of different lengths ranging from 5 to 7 $\mathrm{m}$, and $1 \mathrm{~m}$ width are considered. However, continuous-span slabs and method of analysis were found to have slight effect on results of the reliability analysis. Although ACI 440.1R [14] regulates the design thickness for structural components, in this study, the slab thickness is left adjustable to reach a value that fulfills the strength requirements. The mechanical properties and flexural behavior of SULWECC were taken from different published studies. The compressive strength, density and fiber content by volume fraction of the cementitious composite were taken $24 \mathrm{MPa}, 1000 \mathrm{Kg} / \mathrm{m}^{3}$, and $2 \%$, respectively.

Monte-Carlo Simulation, which is one of the most common techniques in reliability analysis, is used to perform the reliability analysis and calibration process. This iterative process involves the selection of representative design values for consideration; the 
establishment of a probabilistic model by identifying the limit state function, the relevant random variables, and the corresponding statistical parameters; the selection of a proper target reliability index; the evaluation of the reliability level $(\beta)$ of the cases considered; and the adjustment of the resistance factors $(\phi s)$ with the intention of approaching the target reliability level $\left(\beta_{\mathrm{T}}\right)$. Different reliability levels including those established for ductile slabs according to ACI-318 [15] are considered.

Live loads are taken according to ASCE/SEI-7 [16]. Dead load calculations account for both self-weight of the slabs and the weight of a superimposed dead load. The toughness index of experimentally tested SULWECC specimens is calculated to estimate the flexural ductility of SULWECC slabs used in the reliability analysis. The toughness index is calculated in accordance with ASTM C1018 [17]. Due to considerable low elastic modulus of SULWECC, as compared to NWC, the possibility of excessive deflection becomes a major concern and may control the design. However, deflection was not addressed in this study.

\section{SULWECC}

Structural ultra-lightweight ECC is a composite material composed of cement paste; supplementary cementitious materials of different types, such as slag, silica fume, fly ash and pozzolans; engineered lightweight aggregate (LWA) of different sizes and mechanical properties, such as glass bubbles and polymer spheres; admixtures of liquid form to improve the properties of cementitious composite, such as super plasticizer, air entrainer, etc. and synthetic short fibers, such polyvinyl alcohol (PVA) or polypropylene (PP) fibers. LWA-to-cementitious materials $(\mathrm{cm})$ ratio, by weight, ranges between 0.40 and 0.65 , while water-to-cementitious material ratio $(w / \mathrm{cm})$ ranges between 0.25 and $0.5[4,18]$. Due to low specific gravity of engineered LWA, SULWECC has low-to-medium workability [19]. Though the high initial cost of SULWECC represents a major challenge, a pronounced cost reduction is expected when production of large quantities for commercial use begins.

The stress-strain behavior/curve of ECC under uniaxial compression loading consists of four distinguished stages. The curve starts with a linear-elastic ascending stage followed by a nonlinear ascending stage then it goes thought a cracking descending stage until a residual softening descending stage is reached [20,21]. However, the stress-stain behavior of ECC under uniaxial tension loading can be described by a bilinear curve. This curve consists of two stages: first cracking strength stage and ultimate strength stage. Figure (1) shows the stress-strain relationship of structural lightweight and ultra-lightweight ECC under uniaxial tension of three different mixes using the same materials and proportions mentioned earlier [4]. Figure (2) shows the relationship between the cylinder compressive strength and the tensile strengths of the three mixes. The cylinder compressive strength for mix 1 , mix 2 and mix 3 were $41.7,26.2$ and $21.8 \mathrm{MPa}$, respectively, while the corresponding densities were 1450, 1100 and 930 $\mathrm{Kg} / \mathrm{m}^{3}$, respectively. It can be seen that as the density of the ECC increases the compressive strength increases as well. When the compressive strength is $24 \mathrm{MPa}$, it can be shown that the first cracking strength is around $2.1 \mathrm{MPa}$. After the first cracking occurs, the cementitious composite demonstrates plastic yielding and fictitious-strain hardening prior to developing macroscopic cracks. Reference [22] proposed an elastic-perfectly-plastic constitutive model for ECC materials that is function of six parameters. These parameters are the elastic modulus in compression and tension, $E_{0}$ and $E_{t}$, first cracking tensile strength $f_{t}$, ultimate tensile strain capacity $\varepsilon_{\text {tu }}$, ultimate compressive strain capacity $\varepsilon_{\mathrm{cu}}$ and maximum cylinder compressive strength (Figure 3). For Lightweight and ultra-lightweight structural concrete or SULWECC, AASHTO [23] proposed a new equation to estimate the modulus of elasticity $\left(E_{0}\right)$ in MPa.

$$
E_{0}=0.00172 K_{1} \gamma_{c}^{2}\left(f_{c}^{\prime}\right)^{0.33}
$$

where $\gamma_{c}$ is the density of ECC in $\mathrm{Kg} / \mathrm{m}^{3}, f_{c}^{\prime}$ is the compressive strength of ECC in MPa and $K_{1}$ is a factor that can be taken 1.0 unless other information is available.

\section{Flexural Members Considered}

In this study, reliability analysis and calibration process are conducted to predict the flexural resistance factors for the following slab systems:

- Slab system 1 (SS-1): Cast-in-place SULWECC.

- Slab system 2 (SS-2): Cast-in-place SULWECC reinforced with CFRP mesh.

- Slab system 3 (SS-3): Precast SULWECC reinforced with CFRP mesh.

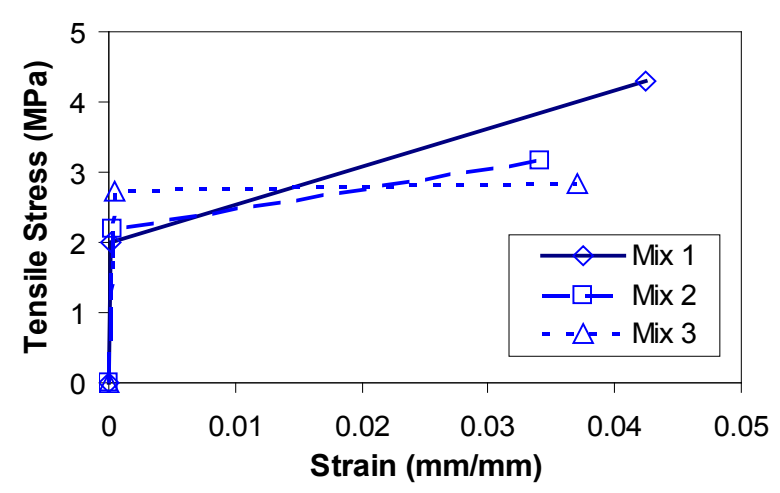

Figure 1. Stress-strain diagram for ECC materials under uniaxial tension 


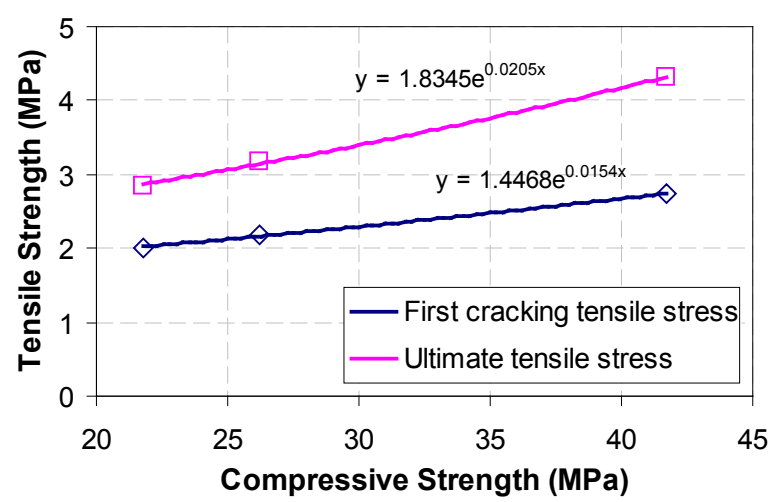

Figure 2. Compressive strength vs. tensile strengths for SULWECC

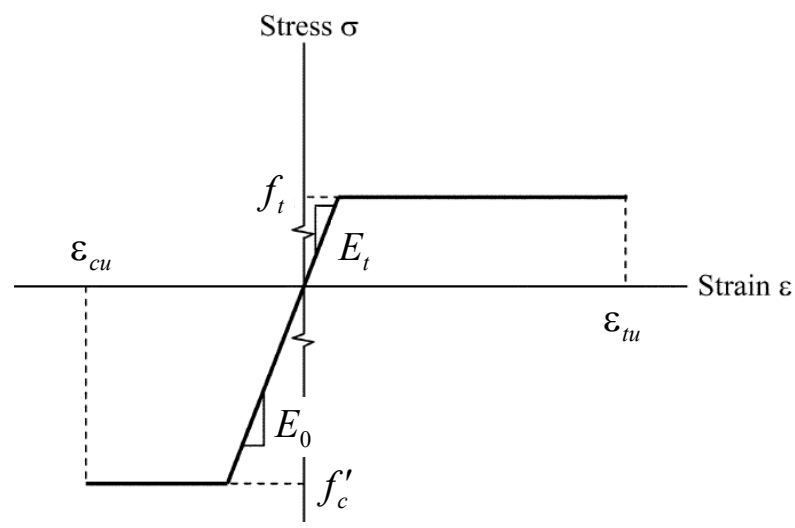

Figure 3. Elastic-perfectly plastic model for ECC materials

In SS-1, continuous reinforcing bars were completely replaced with high volume of randomly dispersed, non-corrosive synthetic short fibers. In SS-2 and SS-3, the reinforcement ratio $\left(\rho_{f}\right)$ of CFRP is selected so that the section is under-reinforced, and the failure mode is tension-controlled. The use of multiple layers of CFRP mesh allows $\rho_{f}$ to meet the required reinforcement ratio. CFRP reinforcement should be placed near the tension surface at locations where maximum moments occur. CFRP mesh is a lightweight non-corrosive material that has some unique characteristics such as high tensile strength and modulus of elasticity, easy to install, requires much less cover when compared to steel rebars and provides excellent bond to concrete. Transverse strands of the CFRP mesh will be beneficial for SS-3 during erection and lifting. Experimental test results have shown that the addition of CFRP mesh in small ratios (under-reinforced section) to SULWECC structural members is associated with an increase of $40 \%$ in the absorbed energy capacity compared to non-reinforced SULWECC. Moreover, the cementitious composite showed enhanced microcracks that allowed for stress distribution by bridging mechanism, and the occurring of greater deflections before rupturing of the CFRP mesh reinforcement [24]. Although it is allowed to use a minimum cover of $6.3 \mathrm{~mm}$, a $13 \mathrm{~mm}$ concrete cover was used in this research. Table 1 shows some of the mechanical properties of CFRP reinforcement.
Table 1. CFRP mesh properties (commercially known as C-Grid)

\begin{tabular}{|c|c|}
\hline Properties & Nominal values \\
\hline Ultimate tensile strength & $2322 \mathrm{MPa}$ \\
\hline Tensile modulus of elasticity $\left(E_{f}\right)$ & $234.5 \mathrm{GPa}$ \\
\hline Elongation at break & $0.99 \%$ \\
\hline Area of strands per unit width & $30.78 \mathrm{~mm}^{2} / \mathrm{m}$ \\
\hline
\end{tabular}

\section{Deterministic Analysis}

The moment capacity of the three slab systems was calculated based on a new model similar to the model proposed by [22] and shown in Figure (3). However, the latter model deviates largely from the real behavior of ECC under uniaxial compression after the maximum compressive strength is reached. Therefore, only the linear elastic part of the compression zone will be used in this study. The new model is composed of two distinct regions, as shown in Figure (4): elastic linear stress distribution that extends up to the maximum compressive strength in the compression zone, and elastic-perfectly-plastic uniform stress distribution in the tension zone. This model is expected to develop microscopic cracks, and the ultimate tensile strain capacity will not be exceeded [4,25], and hence the SULWECC section can be treated as uncracked-section. Furthermore, the linear stress distribution in the tension zone was replaced by a uniform stress distribution, since it covers a very small portion of the stress-strain curve (see Figure 1). This approximation has negligible effect on the results of the analysis.

Figure (5) shows the strain and stress distributions along the cross-sections of SS-1, SS-2 and SS-3 at failure. For all three slab systems, the extreme top surface of the compression zone reaches the maximum compressive strength and its corresponding strain capacity $\left(\varepsilon_{0}\right)$. For SS-2 and SS-3, failure occurs when the tensile strain in the CFRP mesh exceeds the ultimate tensile strain $\left(\varepsilon_{f u}\right)$. This failure will be associated with reduction in the tensile strain at the extreme bottom surface of the SULWECC.

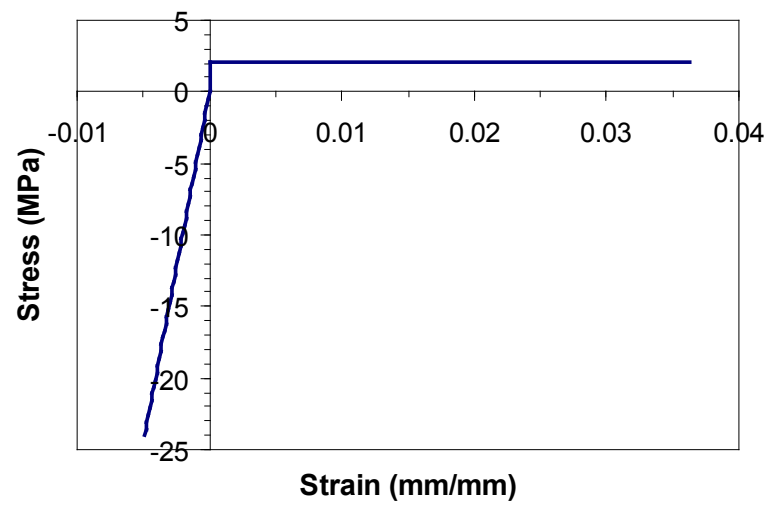

Figure 4. Stress-strain model of the ECC material used in this study

For SS-1, the nominal moment capacity $M_{n}(\mathrm{kN}-\mathrm{m} / \mathrm{m})$ 
can be calculated using Equations (2):

$$
\begin{gathered}
c=\frac{f_{t} t_{s}}{f_{t}+\frac{f_{c}^{\prime}}{2}} \\
M_{n}=\left[\frac{b}{3} f_{c}^{\prime} c^{2}+\frac{b}{2} f_{t}\left(t_{s}-c\right)^{2}\right] \times 10^{-6}
\end{gathered}
$$

where $f_{t}$ is the first cracking strength in $\mathrm{MPa}, f_{c}^{\prime}$ is the maximum compressive strength in $\mathrm{MPa}, b$ is the slab width in $\mathrm{mm}, t_{s}$ is the slab thickness in $\mathrm{mm}$ and $c$ is the distance measured from extreme compression surface to the neutral axis (N.A.) of the cross-section in $\mathrm{mm}$.

For SS-2 and SS-3, the nominal moment capacity $M_{n}$ $(\mathrm{kN}-\mathrm{m} / \mathrm{m})$ can be calculated using Equations (3):

$$
\begin{gathered}
c=\frac{f_{c}^{\prime}}{E_{0}} \frac{d}{\frac{f_{c}^{\prime}}{E_{0}}+\varepsilon_{f u}} \\
M_{n}=\frac{\frac{b}{3} f_{c}^{\prime} c^{2}+\frac{b}{2} f_{t}\left(t_{s}-c\right)^{2}+E_{f} \varepsilon_{f u} A_{f}(d-c)\left(1-\frac{1}{n}\right)}{10^{6}}
\end{gathered}
$$

where $\varepsilon_{f u}$ is the ultimate tensile strain of CFRP mesh, $E_{f}$ is the modulus of elasticity of CFRP mesh in MPa, $A_{f}$ is the area of the reinforcement in $\mathrm{mm}^{2}, d$ is the effective depth of the reinforcing CFRP mesh in $\mathrm{mm}$ and $n$ is the modular ratio $\left(E_{f} / E_{0}\right)$. The first term in the numerator of Equation (3b) is the distance from the neutral axis to the resultant compressive force developed in the concrete, multiplied by the resultant compressive force. The second term is the distance from the neutral axis to the resultant tensile force developed in the concrete, multiplied by the resultant tensile force, while the third term is the distance from the neutral axis to the centroid of the FRP reinforcement, multiplied by the tensile force developed in the CFRP reinforcement.

The controlling load combination is $M_{u}=1.6 M_{L L}+$ $1.2\left(M_{S D}+M_{\mathrm{ow}}\right)$, and the flexural design criteria is $\phi M_{n} \geq M_{u}$, where $M_{u}$ is the maximum factored moment, $\phi$ is the flexural resistance factor, and $M_{D L}$ and $M_{L L}$ are the dead load and live load moments, respectively. A rectangular simply supported slab of width $1 \mathrm{~m}$ and a representative span length $(L)$ of $6 \mathrm{~m}$ are selected for the proposed slab systems. This span length is the upper bound of the most economical length for flat plate slabs [26]. However, span lengths of 5 and $5.5 \mathrm{~m}$ for SS-1, and 6.5 and $7 \mathrm{~m}$ for SS- 2 and SS-3 are also considered in the reliability analysis. As the span length increases, the applied bending moment increases as well, and the need for a second line of defense (CFRP mesh in this case) becomes a necessity. Based on the required number of CFRP mesh layers, the reinforcement thickness $r_{t}$ can be calculated. An average value of $r_{t}=10 \mathrm{~mm}$ was used for all cases. Finally, uniformly distributed live loads $(L L)$ ranging from 0.96 to $7.18 \mathrm{kN} / \mathrm{m}^{2}$ and a uniformly distributed superimposed dead load $(S D)$ of $1.44 \mathrm{kN} / \mathrm{m}^{2}$ are considered.
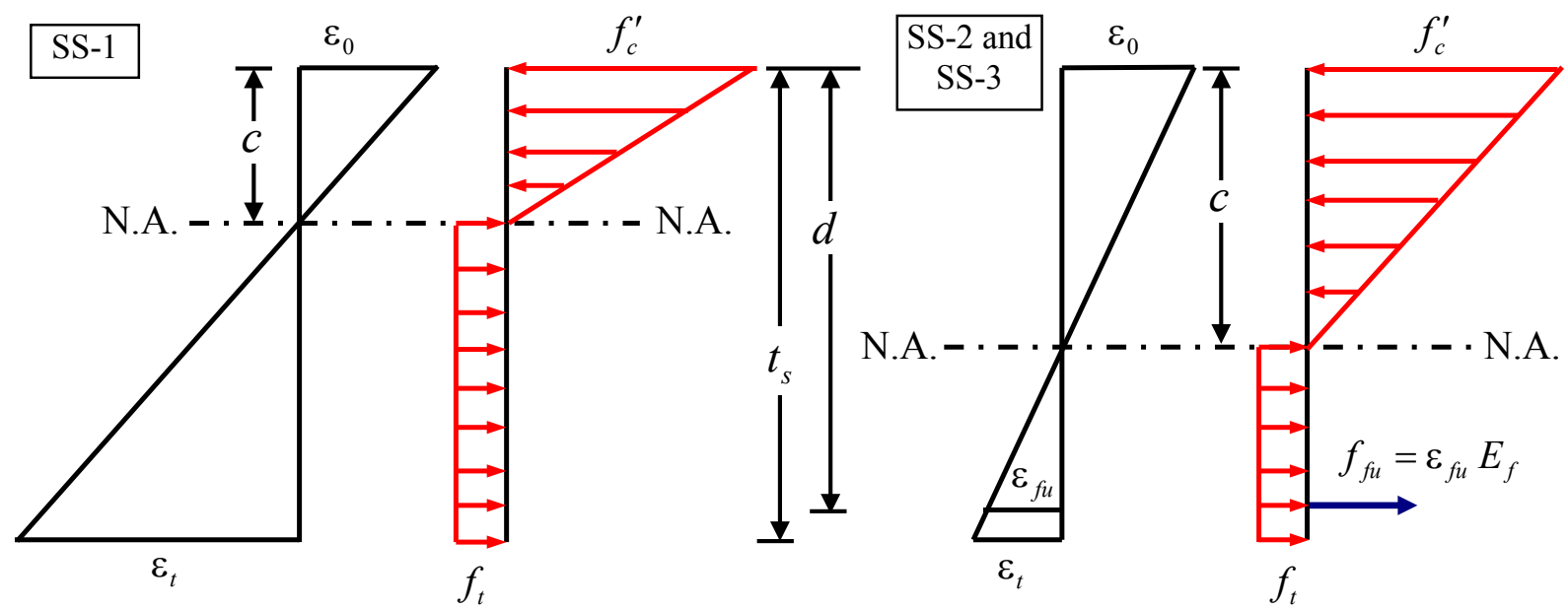

Figure 5. Stress and strain distributions for SS-1, SS-2 and SS-3 at failure (Not to scale) 


\section{Ductility and Toughness Index}

Toughness index is a measure of flexural ductility, energy absorption capacity and the ability of fibrous concrete structural members to bend freely without any sudden failure. The first crack deflection and the corresponding first crack load are essentials in calculating the toughness index accurately. Toughness index is the ratio of the area under load-deflection curve up to specific deflection value, to the area up to the first crack deflection. The area under the load-deflection curve for beams or slabs is a direct measure of the flexural toughness, flexural ductility and energy absorption efficiency of fibrous concrete members. For brittle materials, the toughness index equals 1.0. The following expression can be used to calculate the toughness index $\left(I_{\mathrm{T}}\right)$ [17].

$I_{T}=\frac{\text { Area under (load }- \text { deflection) curve up to limited deflection valve }}{\text { Area under (load - deflection) curve up to first crack deflection } \delta}$

For instant, the toughness index $I_{5}$ is obtained by dividing the area under the load-deflection curve up to a deflection of $3 \delta$ by the area up to first crack. Similarly, dividing the area under the load-deflection curve up to $5.5 \delta$, $10.5 \delta, 15.5 \delta, 20.5 \delta$ and $25.5 \delta$ by the area up to the first crack deflection, will give the values of the toughness indices $I_{10}, I_{20}, I_{30}, I_{40}$ and $I_{50}$, respectively. Thus, the larger the area under load-deflection curve, the higher the flexural ductility and energy absorption. Figure (6) shows a typical load-deflection curve for highly bendable concrete member where toughness index up to $I_{50}$ can be obtained. Such behavior is desirable when high flexural ductility is required, and can be reached only by careful selection of fiber type, fiber concentration, and concrete matrix parameters.

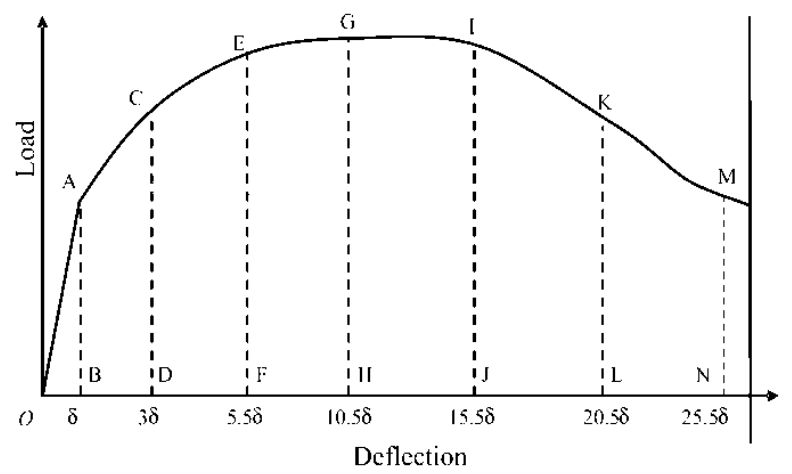

Figure 6. Characteristics of the load-deflection curve used to calculate the toughness index

\section{Reliability Analysis}

Resistance random variables (RVs) relevant to bending moment capacity of SULWECC slab systems considered in this research involve those that account for uncertainties and variations in the properties of materials, such as maximum compressive strength, first cracking tensile strength of SULWECC $\left(f_{t}\right)$, ultimate tensile strain of CFRP mesh $\left(\varepsilon_{f u}\right)$ and modulus of elasticity of CFRP mesh $\left(E_{f}\right)$. Additional random variables should account for variations in geometry of the structural members, such as slab thickness $\left(t_{s}\right)$ and reinforcement effective depth $(d)$; and uncertainties in the method of analysis (the professional factor $P$ ). Variation in cross-sectional area of CFRP reinforcement is insignificant, and is normally treated as a deterministic variable [27]. Uncertainties associated with member geometry and fabrication depend mainly on quality control and precision experienced during the construction process. Normal probability distributions are recommended for all geometric imperfections of reinforced concrete building members [28]. The professional factor can be defined as the ratio of the actual moment capacity to the predicted moment capacity. This factor is typically modeled as normal probability distribution [29]. For models with high variability, the professional factor is modeled using lognormal distributions; otherwise the unrealistic negative strength influences the results. CFRP mesh and ECC RVs are taken from [13] and [22], respectively, while geometry and professional factor RVs are taken from different published studies related to reliability analysis and calibration process [27,28,30,31].

The relevant load RVs are as follows: live load $(L L)$, superimposed dead load $(S D)$ and own-weight or self-weight load (O.W.). Coefficient of variation (COV), bias factor $(\lambda)$, and statistical distribution type are used to define the statistical parameters of RVs. Bias factor is the ratio of mean value to nominal value. Load RVs data are taken from [27]. RVs and their corresponding statistical parameters used in this study are listed in Table 2. Each statistical parameter of the random variables acts as a reducing factor to lower the reliability level of the SULWECC.

Table 2. Statistical parameters of the RVs

\begin{tabular}{|c|c|c|c|}
\hline $\mathrm{RV}^{*}$ & Nominal Value & COV & $\lambda$ \\
\hline$f_{c}^{\prime}(\mathrm{MPa})$ & 24 & 0.042 & 1.07 \\
\hline$f_{t}(\mathrm{MPa})$ & 2.1 & 0.067 & 1.1 \\
\hline$E_{f}(\mathrm{GPa})$ & "See Table 1 " & 0.08 & 1.04 \\
\hline$\varepsilon_{f}$ & 0.0099 & 0.05 & 1.2 \\
\hline$t_{s}(\mathrm{~mm})$ & variable & 0.05 & 1.0 \\
\hline$d(\mathrm{~mm})($ cast-in-place $)$ & $t_{s}-\left(12+r_{t} / 2\right)$ & 0.12 & 0.92 \\
\hline$d(\mathrm{~mm})(\mathrm{precast})$ & $t_{s}-\left(12+r_{t} / 2\right)$ & 0.06 & 1.00 \\
\hline$P$ & 1 & 0.05 & 0.98 \\
\hline$D L\left(\mathrm{kN} / \mathrm{m}^{2}\right)$ & $1.44+$ slab O.W. & 0.12 & 1.05 \\
\hline$L L\left(\mathrm{kN} / \mathrm{m}^{2}\right)$ & $0.98-7.18$ & 0.18 & 1.00 \\
\hline
\end{tabular}

*All RVs are normal distribution except live load, which is extreme type I.

The optimum value of target reliability index $\left(\beta_{\mathrm{T}}\right)$ depends on many factors, such as failure mode (ductile or brittle), severity of consequences, cost associated with increasing the level of safety, degree of load 
sharing/distribution and existing levels of safety. In ACI 440.1R [14] and ACI 318 [15], the commonly used value of target reliability index $\left(\beta_{\mathrm{T}}\right)$ for reinforced concrete flexural members is 3.5. This level of safety is based on two factors: the failure modes are ductile and the materials being used are well proved to be safe over a long period of time. However, in cast-in-place slab system, there is a remarkably large degree of load distribution, and the system has a substantially larger safety level than that for beams. Therefore, a reduced value of $\beta_{\mathrm{T}}=2.5 \mathrm{can}$ be used [32]. For precast slab systems, the degree of load sharing/distribution is similar to beams, and $\beta_{\mathrm{T}}$ should be taken 3.5. It is worth to mention that, in this study, the reliability analysis was performed based on strength requirements, although deflection could control the design.

Monte-Carlo Simulation was performed using a model created in Visual Basic for Applications to carry out reliability analysis and calibration process. To ensure the validity of the model, the results of more than $10^{3}$ cycles were traced out and some of them were checked through hand calculations. The total number of simulated cycles needed to approach convergence was $5 \times 10^{5}$. The limit state function $g=P M_{n}-M_{u}$ should be identified in terms of all RVs and the nominal moment capacity $\left(M_{n}\right)$ should satisfy $M_{\mathrm{n}}=M_{\mathrm{u}} / \phi$. Failure occurs when the maximum applied factored moment $\left(M_{\mathrm{u}}\right)$ on the flexural member exceeds the flexural moment capacity $\left(P M_{n}\right)$ (i.e. $\mathrm{g}<0$ ). The probability of failure $\left(\mathrm{p}_{\mathrm{f}}\right)$ is calculated using Equation (5), while the inverse standard normal distribution of the probability of failure is used to calculate the reliability index $\beta=-\Phi^{-1}\left(p_{\mathrm{f}}\right)$. The flexural resistance factor $(\phi)$ is adjusted until minimum target reliability index $\left(\beta_{\mathrm{T}}\right)$ is approached. The nominal moment capacity $\left(M_{n}\right)$ and the maximum applied factored moment $\left(M_{\mathrm{u}}\right)$ on the flexural slab systems are defined in Section 6: Deterministic Analysis.

$$
\mathrm{p}_{\mathrm{f}}=\frac{\text { Number of failures }}{\text { Total number of cycles }}
$$

\section{Calculations}

The typical load ratio in reliability analysis is $D L /(D L+L L)$, where $D L$ and $L L$ are the dead load and live load in $\mathrm{kN} / \mathrm{m}^{2}$, respectively. The reinforcement ratio $(\rho)$ was set to $\sim 0.1 \%$ for CFRP reinforced slab systems. Due to the ability of SULWECC slab systems to exhibit high ductile behavior prior to failure, the target reliability level $\left(\beta_{\mathrm{T}}\right)$ of 2.5 for SS- 1 and SS-2, and $\beta_{\mathrm{T}}$ of 3.5 for SS-3, were considered. The reliability index $(\beta)$ associated with the resistance factor $(\phi)$ was calculated for a wide range of the load ratios. For comparison, the calculations were repeated to determine resistance factors needed to obtain different reliability levels. The use of reliability levels other than $\beta_{\mathrm{T}}$ may become justifiable, if the differences in performance between the proposed slab systems and steel/FRP reinforced concrete slabs are considered. These differences become evident when considering the method used to calculate the moment capacity of the cross-section, the method used to reinforce the slab, and the method used to evaluate the ductile behavior. Raising the reliability target level would provide the necessity for lower resistance factors. Appendix A illustrates the flowchart of performing the Monte-Carlo Simulation, for and any given live and dead load, of the proposed slab systems.

Figure (7) shows load-deflection curves for three experimentally tested non-reinforced and CFRP mesh reinforced SULWECC specimens obtained from third-point loading flexural test. The reinforcement ratio $\left(\rho_{f}\right)$ was around 0.0011 [24]. The SULWECC mix was made up of cement paste, silica fume, fly ash, a combination of three different types of engineered LWA, PVA fibers with $V_{\mathrm{f}}=1.9 \%$ and high-range water reducing admixture. Due to the substantial material similarity between the experimentally tested SULWECC specimens and the SULWECC slabs used in the reliability analysis, and their ability to meet similar tensile and compressive ultimate strain capacities, these load-deflection curves will be considered as a baseline for evaluating the flexural behavior of the slab systems proposed in this study. The cylinder compressive strength and density were $18 \mathrm{MPa}$ and $620 \mathrm{Kg} / \mathrm{m}^{3}$, respectively. The toughness index was calculated in accordance with ASTM C 1018 [17] for fibrous concrete, and used as a measure of ductility.
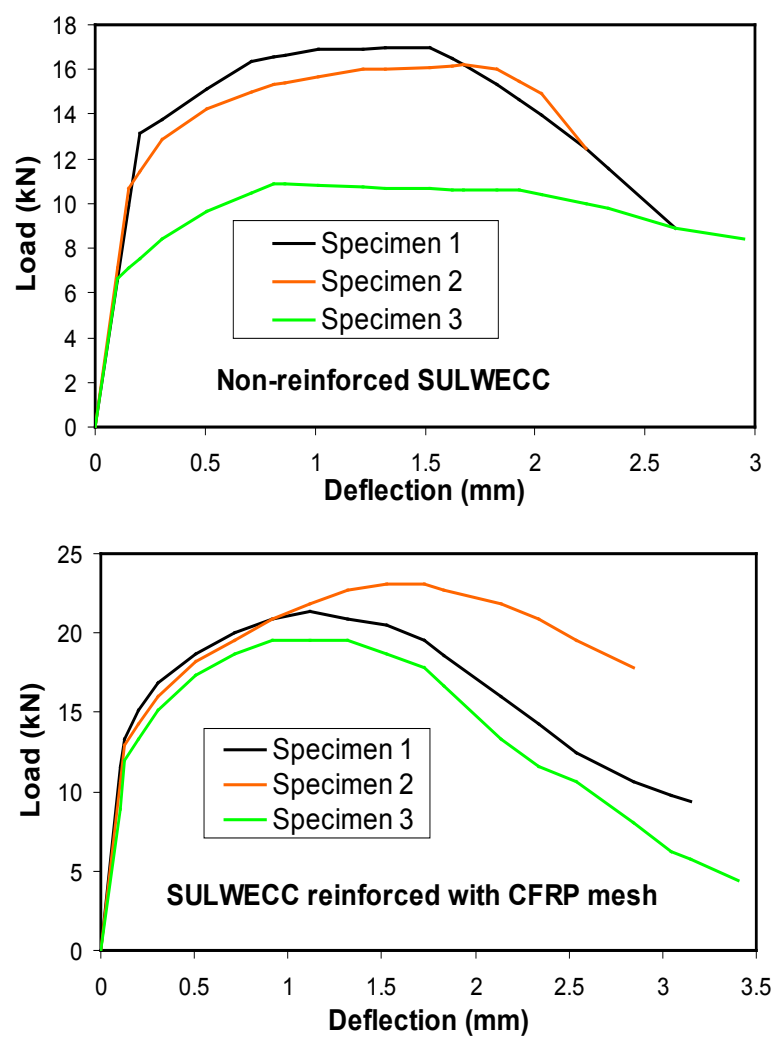

Figure 7. Load-deflection curves of SULWECC 


\section{Results and Discussion}

Figs. 8 shows the relationship between the flexural reliability index and the load ratio $D L /(D L+L L)$ for the three different slab systems considered in this study. The lowest load ratio values are associated with the greatest live load values. Based on the results of the analysis, an excellent linear correlation was observed between load ratios and reliability indices. For SS-1 and SS-2, it can be seen that the required resistance factors $(\phi s)$ to achieve a target reliability index of 2.5 are 0.69 and 0.67 , respectively. The process was repeated for different resistance factors to obtain higher reliability indices of 2.75 and 3.0. For SS-3, it can be observed that to achieve a target reliability index of 3.5 , a value of $\phi=0.59$ is required. Again, the process was repeated for different resistance factors to obtain higher and lower reliability indices of 3.75 and 3.25. The use of lower resistance factor can be justified from the fact that the degree of load sharing of precast cementitious composite slab panels is higher than beams, especially if the width is significantly greater than $1.0 \mathrm{~m}$, and lower than cast-in-place slabs.
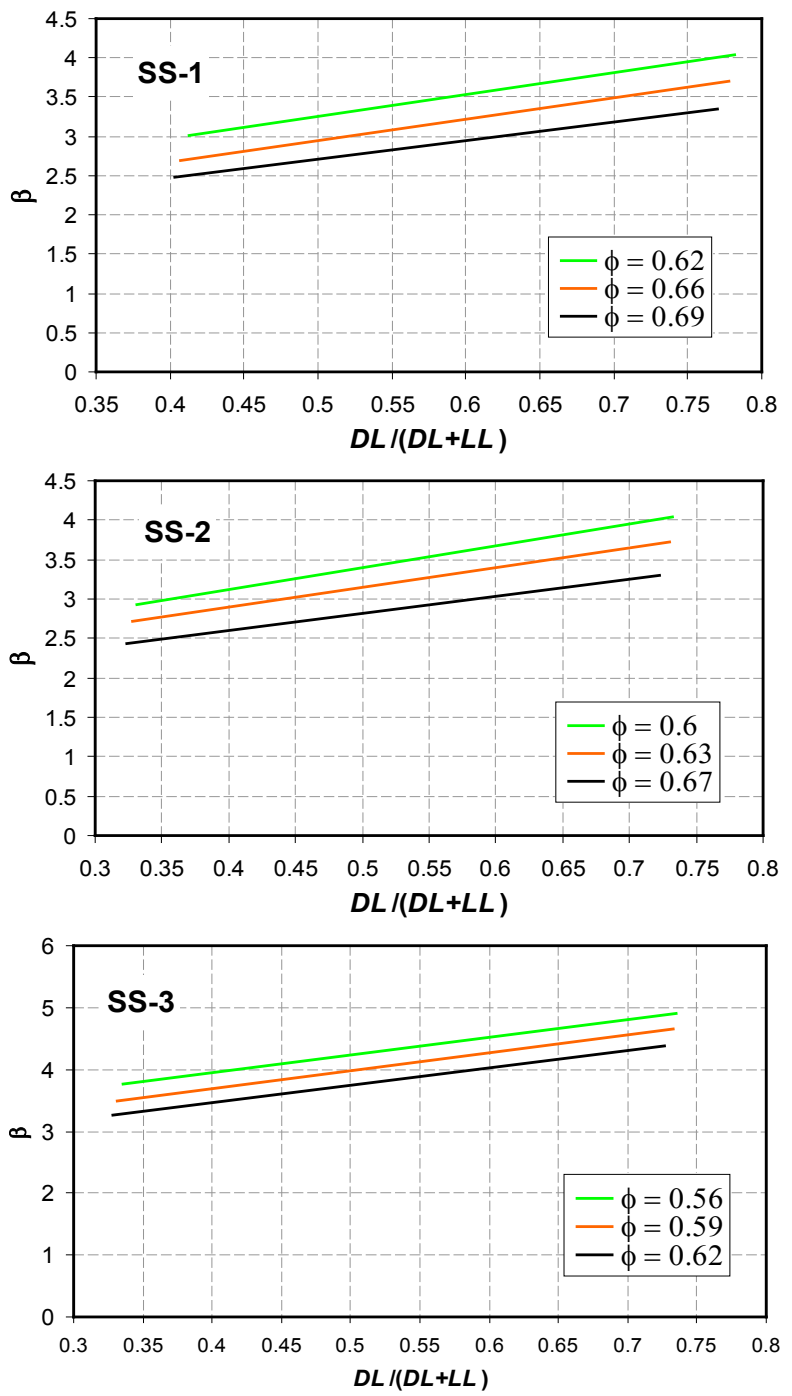

Figure 8. Flexure reliability index vs. load ratios
For SS-1 and SS-2, the resistance factors are higher than the currently specified values for members reinforced with FRP bars, when failure mode is tension-controlled or compression-controlled. For SS-3, the resistance factors are higher than the specified value for members reinforced with FRP bars, when failure mode is tension-controlled. Recall that the resistance factors specified by [14] for concrete members reinforced with non-ductile FRP bars varies from $\phi=0.55$ for tension-controlled sections to $\phi=$ 0.65 for compression-controlled sections. However, the resistance factors are much below the value of 0.90 for tension controlled, steel-reinforced concrete members needed to achieve similar safety levels. For comparison, the calculations were repeated to determine the effect of using span lengths of 5 and $5.5 \mathrm{~m}$ on SS-1, and span lengths of 6.5 and $7 \mathrm{~m}$ on SS-2 and SS-3. The span length of the slab was found to have a negligible effect on reliability index $\beta$, when $\phi$ is constant. Live load, on the other hand, was found to have a more pronounced effect on reliability results due to the characteristics of extreme type I distribution used to model the $L L$. For SS-1, SS-2 and SS-3, the maximum slab thicknesses needed to satisfy the strength requirement were $L / 17, L / 29$ and $L / 27$, respectively, while the average values were $L / 22, L / 37$ and $L / 35$, respectively. For the same moment capacity, and using SS- 1 as a baseline for comparison, a reduction in slab thickness of $\sim 38 \%$ was associated with the use of SS-2 and SS-3. The increase of live load, and consequently the applied moment, beyond the $7.18 \mathrm{kN} / \mathrm{m}^{2}$ (the maximum $L L$ considered in this study) will be associated with increase in slab thickness to satisfy the strength requirements, and a decrease in the degree of reliability, as shown in Figures (9) and (10). For both cases, the design becomes more expensive and the safety level becomes undesirable. On the other hand, the increase of reliability index value beyond the reliability target value will result in a decrease in the flexural resistance factor $(\phi)$ and an increase in the slab thickness, and hence the design becomes more expensive. However, higher safety levels will be provided.

As the elastic modulus of SULWECC is considerably lower than that of NWC, and the slab thicknesses needed to satisfy the strength requirements are much below the minimum recommended value of $L / 13$ for one-way non-prestressed concrete slabs reinforced with non-ductile FRP bars, excessive deflections become extremely critical and may govern the design. However, deflection was not addressed in this study. It is suggested that deflection is calculated, and the slab thickness is changed accordingly. The result will be a design that meets strength, ductility, as well as deflection requirements. It is worth mentioning here that flexural deflection becomes less critical in structures that consist of multiple continuous frames, such as two-way flat plate floors.

The reinforcement ratios for the SS-2 and SS-3 slab systems varied from $0.95-1.04 \times 10^{-3}$, with the highest values associated with the greatest live load values. It can 
be argued that the use of SULWECC slabs will be associated with significant decrease in size and reinforcement of the supporting structural components, such as columns, beams, and foundations, resulting in problems related to instability and low stiffness. ACI 440.1R [14] and ACI 318 [15] have requirements and specifications that regulate the design of such supporting members (usually NWC) and cannot be changed or overridden by the designers.

ULWAC has been used in constructing privet houses and exterior walls of governmental and office buildings in Germany [33]. In addition, some State Departments of Transportation, such as Virginia Departments of Transportation (VDOT) [34], have provided special provisions for bridge decks made with lightweight concrete where no minimum density for concrete is specified.
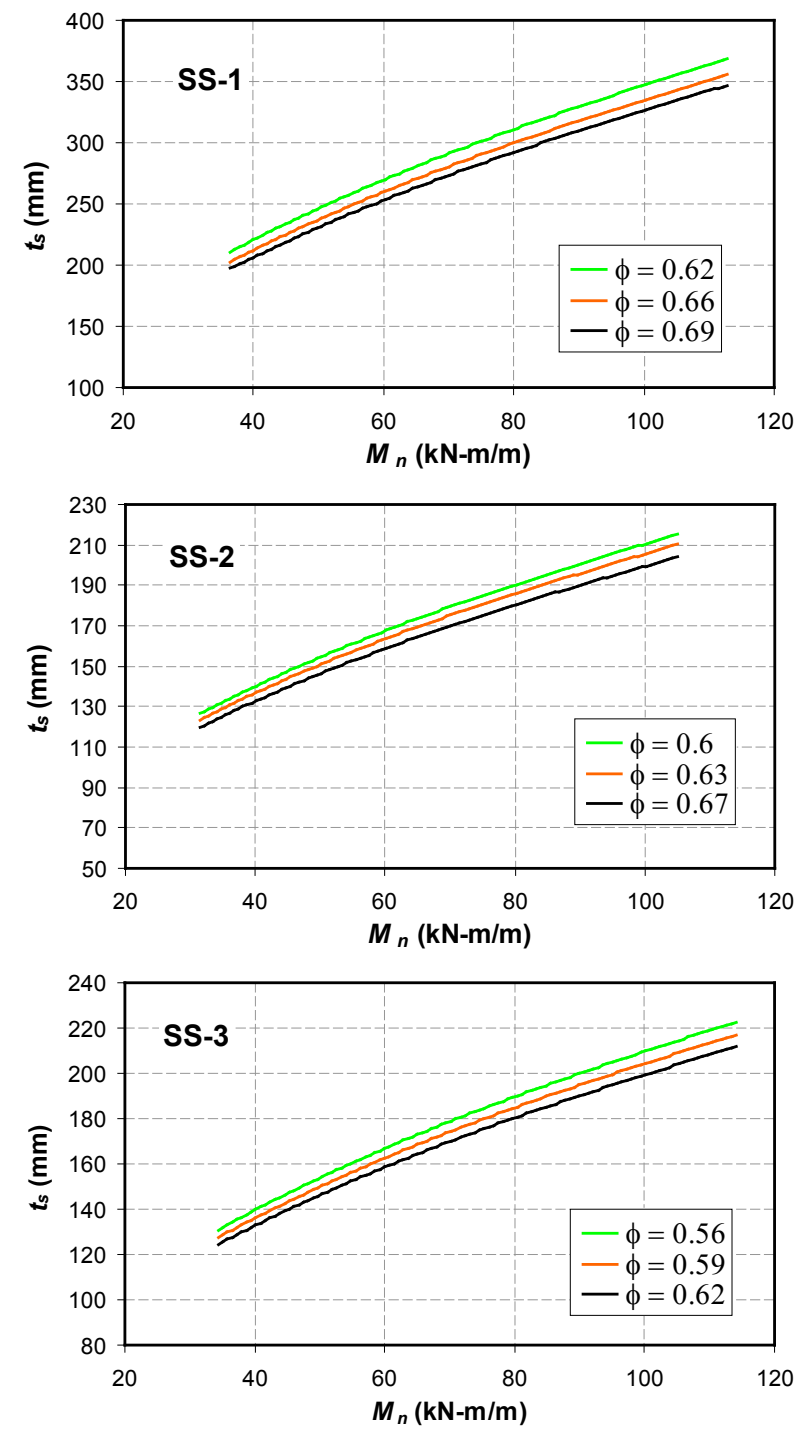

Figure 9. Moment capacity vs. slab thickness for different $\phi \mathrm{s}(L=6 \mathrm{~m})$
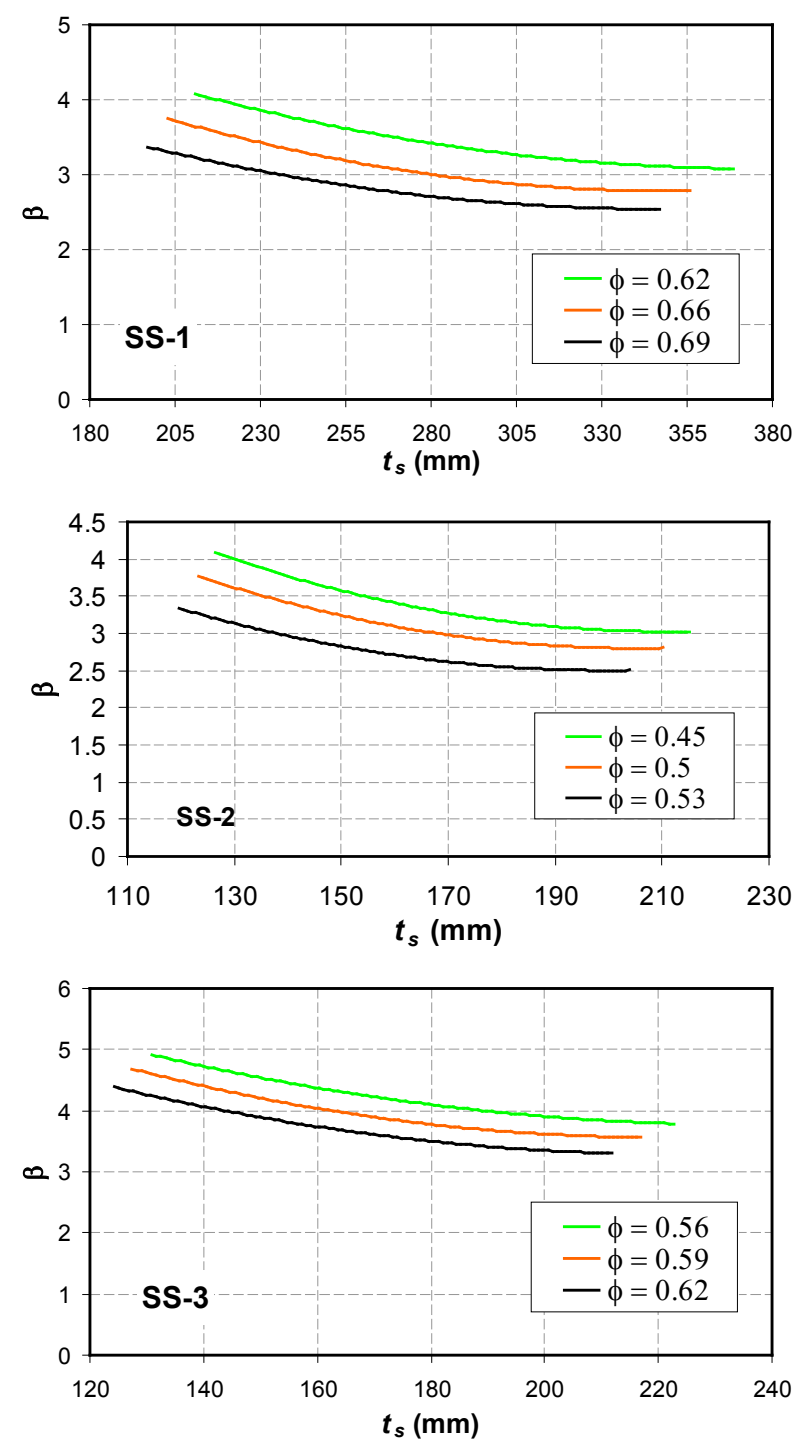

Figure 10. Slab thickness vs. reliability index for different $\phi \mathrm{s}(L=6$ $\mathrm{m})$

Table 3 shows the toughness indices for SULWECC specimens having load-deflection response illustrated in Figure (7). It can be seen that the toughness indices are higher than those assigned for perfectly elastic-plastic materials. High toughness indices are attributed to the sufficiently long load-deflection curves and the low values of the first crack loads, resulting in reduction of the area under load-deflection curve up to the first crack deflection. Moreover, the computed values satisfy the observed range of toughness indices found in [17] for fibrous concrete, and up to $I_{50}$ is obtained. Similar results were obtained by [35] for ECCs, and up to $I_{40}$ was obtained. However, some of the SULWECC specimens have shown better performance (higher ductility). 
Table 3. Toughness indices for ductile SULWECC specimens

\begin{tabular}{|c|c|c|c|c|c|c|c|c|c|}
\hline \multicolumn{10}{|c|}{ Values of toughness indices } \\
\hline $\begin{array}{c}\text { Index } \\
\text { Designation }\end{array}$ & $\begin{array}{c}\text { Deflection } \\
\text { Criterion }\end{array}$ & $\begin{array}{c}\text { Elastic-Plastic } \\
\text { Material }\end{array}$ & $\begin{array}{c}\text { ASTM C1018 } \\
\text { Observation for } \\
\text { Fibrous Concrete }\end{array}$ & Specimen 1 & Specimen 2 & Specimen 3 & Specimen 1 & Specimen 3 & Specimen 3 \\
\hline I5 & $3 \delta$ & 5.0 & 1 to 6 & 5.41 & 5.72 & 5.53 & 5.75 & 5.67 & 5.72 \\
\hline I10 & $5.5 \delta$ & 10.0 & 1 to 12 & 11.72 & 12.62 & 12.42 & 12.81 & 12.77 & 12.98 \\
\hline I20 & $10.5 \delta$ & 20.0 & 1 to 25 & 23.86 & 27.49 & 28.33 & 28.46 & 29.14 & 29.14 \\
\hline I30 & $15.5 \delta$ & 30.0 & 1 to 38 & - & 39.3 & 44.36 & 43.15 & 46.99 & 43.97 \\
\hline I40 & $20.5 \delta$ & 40.0 & 1 to 50 & - & - & 60.19 & 54.15 & 63.25 & 54.2 \\
\hline I50 & $25.5 \delta$ & 50.0 & 1 to 63 & - & - & 74.76 & - & - & 60.41 \\
\hline
\end{tabular}

\section{Conclusions}

This study presents reliability analysis and calibration process to predict the flexural resistance factors $(\phi s)$ for corrosion-free, cast-in-place and precast structural ultra-lightweight ECC (SULWECC) slab systems to meet target reliability indices established for ductile structural members. Non-reinforced SULWECC and SULWECC internally reinforced with carbon FRP (CFRP) mesh were considered. The reinforcement ratio $(\rho)$ of the CFRP mesh was selected so that the section is under-reinforced $(\rho=\sim$ $0.001)$. The target reliability indices $\left(\beta_{\mathrm{T}}\right)$ for cast-in-place and precast slab systems were taken 2.5 and 3.5, respectively. The following conclusions can be drawn from the present study:

1. The flexural resistance factors $(\phi s)$ were found to be higher than the currently specified value of 0.55 for tension-controlled NWC members reinforced with non-ductile FRP bars.

2. The results of this study suggest the use of $\phi=0.69$ for non-reinforced cast-in-place SULWECC slabs, $\phi$ $=0.67$ for cast-in-place SULWECC slabs reinforced with CFRP mesh and $\phi=0.59$ for precast SULWECC slabs reinforced with CFRP mesh.
3. The maximum slab thickness $\left(t_{s}\right)$ needed to satisfy the strength requirement ranged from $L / 29$ to $L / 17$, while the average $t_{s}$ ranged from $L / 37$ to $L / 22$.

4. Due to significant decrease in slab thickness needed to satisfy the strength requirements and considerable low elastic modulus of SULWECC slab systems, excessive deflection becomes a serious problem and may govern the design. Using deeper sections will solve the deflection problem.

5. The toughness indices were found to be higher than the limits assigned for perfectly elastic-plastic materials, and satisfy the observed range of toughness indices for fibrous concrete found in ASTM C1018.

6. The new slab systems have the potential to be efficient if used in two-way flat plate floors, by reducing the slab thickness needed to satisfy the strength requirements. They can also be successfully used in the field of precast concrete construction.

7. Finally, more experimental work and larger database of SULWECC slabs and SULWECC slabs reinforced with carbon FRP mesh are needed for better statistical evaluation of uncertainties and variations in materials properties, geometry of the structural members, and professional factor. 


\section{Appendix A}

\section{A-1. Flowchart of performing the Monte-Carlo Simulation of the proposed slab systems.}

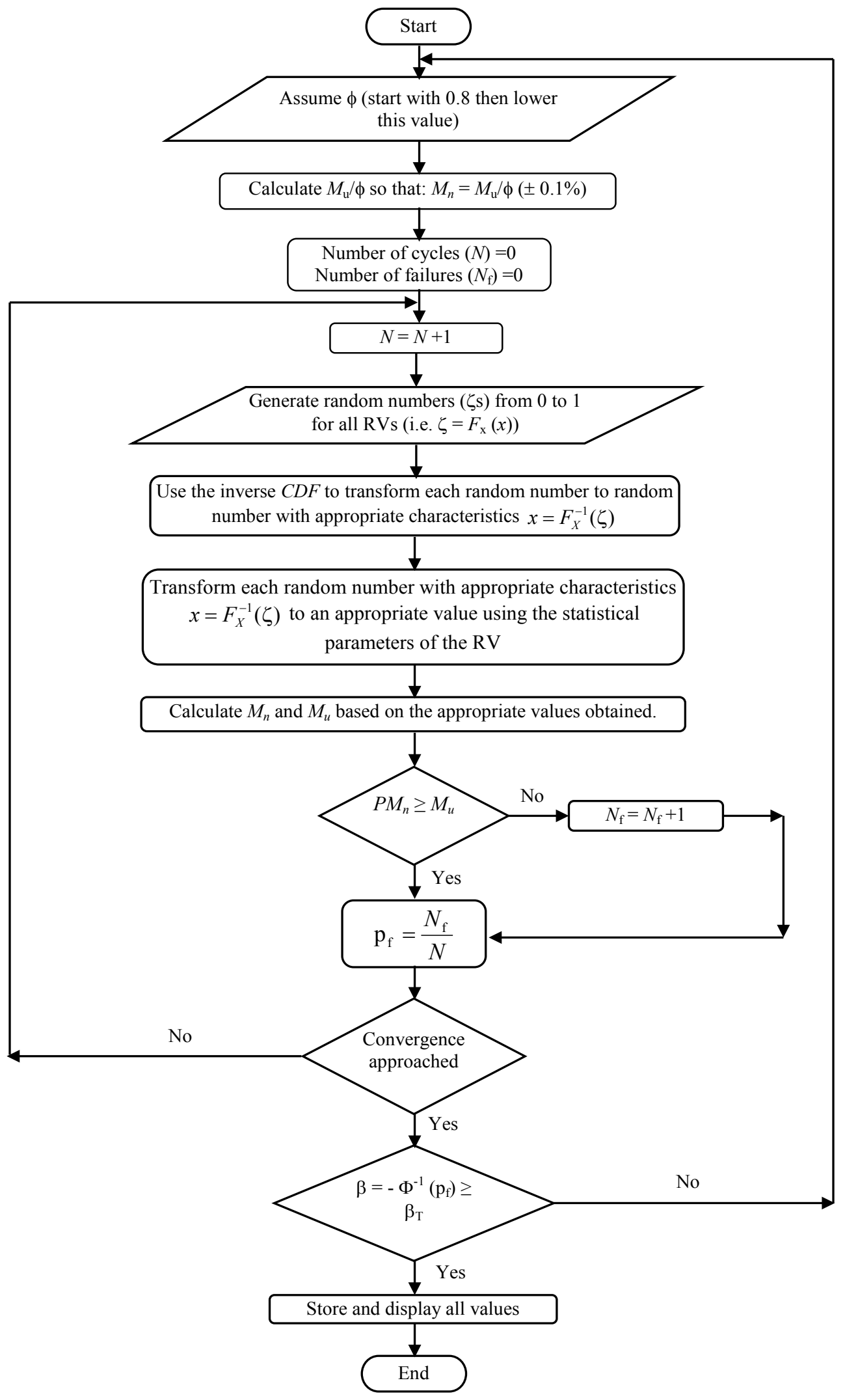

Where $C D F$ is the cumulative distribution function $F_{X}(x)$. 


\section{REFERENCES}

[1] J. Bilcik, I. Holly. Effect of reinforcement corrosion on bond behaviour, Procedia Engineering, Vol.65, 248-253, 2013. DOI: $10.1016 /$ j.proeng.2013.09.038

[2] H. G. Harris, W. Somboonsong, F. K. Ko. New ductile hybrid FRP reinforcing bar for concrete structures, ASCE Journal of Composites for Construction, Vol.2, No.1, 28-37, 1998. DOI: 10.1061/(ASCE)1090-0268(1998)2:1(28)

[3] M. M. S Cheung, T. K. C Tsang. Behaviour of concrete Beams reinforced with hybrid FRP composite bars, Advances in Structural Engineering Vol.13, No.1, 81-93, 2010. DOI: $10.1260 / 1369-4332.13 .1 .81$

[4] S. Wang, V. C. Li. Lightweight engineered cementitious composites (ECC), Fifth International RILEM Workshop on High Performance Fiber Reinforced Cement Composites (HPFRCC5), MI, USA, 379-390, 2003. https://www.researc hgate.net/publication/280229383_Lightweight_ECC

[5] E. Yasar, C. D. Atis, A. Kilic, H. Gulsen. Strength properties of lightweight concrete made with basaltic pumice and fly ash, Materials Letters, Vol.57, No.15, 2267-2270, 2003. DOI: 10.1016/S0167-577X(03)00146-0

[6] Q. L. Yu, P. Spiesz, H. J. H Brouwers. Ultra-lightweight concrete: conceptual design and performance evaluation, Cement and Concrete Composites, Vol.61, 18-28, 2015. DOI: 10.1016/j.cemconcomp.2015.04.012

[7] T-P. Huynh, V-H. Pham, T-K. Lam, N-T. Ho. Experimental research on the performance of polypropylene fiber foamed ultra-lightweight composites. Civil Engineering and Architecture Vol.8, No.4, 654-661, 2020. DOI: 10.13189/ce a.2020.080429

[8] ACI 213R-03. Guide for structural lightweight aggregate concrete, American Concrete Institute: Farmington Hills, MI, 2003.

[9] F. Yuan; J. Pan, C. K. Y. Leung. Flexural behaviors of ECC and concrete/ECC composite beams reinforced with basalt fiber-reinforced polymer, Journal of Composites for Construction, Vol.17, No.5, 591-602, 2013. DOI: 10.1061/(ASCE)CC.1943-5614.0000381

[10] V. C. Li and S. Wang. Flexural Behaviors of Glass Fiber-Reinforced Polymer (GFRP) Reinforced Engineered Cementitious Composite Beams, ACI Materials Journal, Vol.99, No.1, 11-21, 2002.

[11]B. Behnam, C. Eamon. Resistance factors for ductile FRP-reinforced concrete flexural members, ASCE Journal of Composites for Construction, Vol.17, No.4, 942-950, 2013. DOI: 10.1061/(ASCE)CC.1943-5614.0000363

[12] H. Jawaheri Zadeh, A. Nanni. Reliability analysis of concrete beams internally reinforced with fiber-reinforced polymer bars, ACI Structural Journal, Vol.110, No.6, 1023-1031, 2013.

[13] C. K. Shield, T. V. Galambos, P. Gulbrandsen. On the history and reliability of the flexural strength of FRP reinforced concrete members in ACI 440.1R, 10th International
Symposium on Fiber Reinforced Polymer Reinforcement for Concrete Structures, ACI Special Publication, 1-18, 2011.

[14]ACI 440.1R. Guide for the design and construction of concrete reinforced with FRP bars, American Concrete Institute, Farmington Hills, MI, 2015.

[15] ACI 318. Building code requirements for structural concrete and commentary, American Concrete Institute, Farmington Hills, MI, 2019.

[16] ASCE/SEI-7. Minimum design loads for buildings and other structures, American Society of Civil Engineers, Reston, VA, 2010

[17] ASTM C1018. Standard test method for flexural toughness and first-crack strength of fiber-reinforced concrete, American Society for Testing Materials, West Conshohocken, PA, 1997.

[18]B. Behnam, A. Al-Fraihat. Properties of fiber-reinforced structural and non-structural ultra lightweight aggregate concrete, International Review of Civil Engineering, Vol.10, No.5, 227-234, 2019. DOI: 10.15866/irece.v10i5.16971

[19]F. Moutassem. Ultra-lightweight EPS concrete: Mixing procedure and predictive models for compressive strength. Civil Engineering and Architecture, Vol.8, No.5, 963-972, 2020. DOI: $10.13189 /$ cea.2020.080523

[20] J. Zhou, J. Pan, C. K. Y. Leung. Mechanical behavior of fiber-reinforced engineered cementitious composites in uniaxial compression, ASCE Journal of Materials in Civil Engineering, Vol.27, No.1, 10 pages, 2015. Doi: 10.1061/(ASCE)MT.1943-5533.0001034

[21] M. Hassanpoura, P. Shafigh, H. Bin Mahmud. Lightweight aggregate concrete fiber reinforcement-A review, Construction and Building Materials, Vol.37, 452-461, 2012. DOI: 10.1016/j.conbuildmat.2012.07.071

[22] M. D. Lepech and V. C. Li. Large-scale processing of engineered cementitious composites, ACI Materials Journal, Vol. 105, No.4, 358-366, 2008. https://www.researchgate.ne t/publication/280224054_Large_Scale_Processing_of_Engi neered_Cementitious_Composites

[23] AASHTO LRFD Bridge Design Specifications, 8th edition, American Association of State and Highway Transportation Officials, Washington, D.C., 2017.

[24] Laval University. "Maximus", NCCC Design Paper, Laval University, Québec, 17 pages, 2014.https://canoe.slc.engr.w isc.edu/Design\%20Papers/2014\%20-\%20Laval.pdf

[25] V. C. Li. Tailoring ECC for Special Attributes: A Review, International Journal of Concrete Structures and Materials, Vol.6, No.3, 135-144, 2012. DOI: 10.1007/s40069-012-001 8-8

[26] J. K. White, J. G. MacGregor. Reinforced Concrete: Mechanics and Design, Pearson Education, Inc., Upper Saddle River, NJ, 2011.

[27] A. S. Nowak, M. M. Szerszen. Calibration of design code for building (ACI 318), Part 2: Reliability analysis and resistance factors, ACI Structural Journal, Vol.100, No.3, 383-391, 2003.

[28] S. A. Mirza, J. G. MacGregor. Variations in dimensions of reinforced concrete members, Journal of the Structural 
Division, Vol.105, No.4, 751-766, 1979.

[29]R. Lu, Y. Luo, J. P. Conte. Reliability evaluation of reinforced concrete beams, Structural Safety, Vol.14, 277-298, 1994. DOI: 10.1016/0167-4730(94)90016-7

[30] A. S. Nowak, A. M. Rakoczy, and E. K. Szeliga. Revised statistical resistance models for R/C structural components, ACI Special Publication, Vol.284, 61-76, 2012. https://www.researchgate.net/publication/282069413_Revis ed_statistical_resistance_models_for_RC_structural_compo nents

[31] B. Ellingwood, T. V. Galambos, J. G. McGregor, C. A. Cornell. Development of a Probability Based Load Criterion for American National Standard A58, National Bureau of Standards Special Report 577, U.S. Department of Commerce, 1980. https://nvlpubs.nist.gov/nistpubs/Legacy/
SP/nbsspecialpublication577.pdf

[32] A. S. Nowak, K. R. Collins. Reliability of structures, CRC Press, Florida, 2013.

[33] K-C. Thienel. Application of lightweight concrete, Nordic Mini-Seminar: Structural Lightweight Aggregate Concrete, Nordic Concrete Federation, 6-9, 2019. https://www.researc hgate.net/publication/331231809_Application_of_Lightwei ght_Concrete

[34] VDOT. Road and bridge specifications, Richmond, VA, 2016.

[35] H. S. Said, Abdul H. Razak, I. Othman. Flexural behavior of engineered cementitious composite (ECC) slabs with polyvinyl alcohol fibers, Construction and Building Materials, Vol.75, 176-188, 2015. DOI: 10.1016/j.conbuild mat.2014.10.036 